\title{
International comparison of the factors influencing reimbursement of targeted anti-cancer drugs
}

\author{
Carol Sunghye Lim ${ }^{1 \dagger}$, Yun-Gyoo Lee ${ }^{2+}$, Youngil Koh ${ }^{3}$ and Dae Seog Heo ${ }^{1,3^{*}}$
}

\begin{abstract}
Background: Reimbursement policies for anti-cancer drugs vary among countries even though they rely on the same clinical evidence. We compared the pattern of publicly funded drug programs and analyzed major factors influencing the differences.
\end{abstract}

Methods: We investigated reimbursement policies for 19 indications with targeted anti-cancer drugs that are used variably across ten countries. The available incremental cost-effectiveness ratio (ICER) data were retrieved for each indication. Based on the comparison between actual reimbursement decisions and the ICERs, we formulated a reimbursement adequacy index (RAl): calculating the proportion of cost-effective decisions, either reimbursement of cost-effective indications or non-reimbursement of cost-ineffective indications, out of the total number of indications for each country. The relationship between RAI and other indices were analyzed, including governmental dependency on health technology assessment, as well as other parameters for health expenditure. All the data used in this study were gathered from sources publicly available online.

Results: Japan and France were the most likely to reimburse indications (16/19), whereas Sweden and the United Kingdom were the least likely to reimburse them ( $5 / 19$ and $6 / 19$, respectively). Indications with high cost-effectiveness values were more likely to be reimbursed $(\rho=-0.68, P=0.001)$. The three countries with high RAl scores each had a healthcare system that was financed by general taxation.

Conclusions: Although reimbursement policies for anti-cancer drugs vary among countries, we found a strong correlation of reimbursements for those indications with lower ICERs. Countries with healthcare systems financed by general taxation demonstrated greater cost-effectiveness as evidenced by reimbursement decisions of anti-cancer drugs.

Keywords: Anti-cancer drugs, Reimbursement, Cost-effectiveness

\section{Background}

Each country has limited financial resources devoted to public healthcare; thus, how to best allocate these finite resources in an efficient and justifiable way poses a great challenge at the national level. Especially, expenditure on cancer drugs imposes substantial burdens on patients and providers of health insurance in all countries [1-4]. The costs of cancer drugs have arisen concurrently with the shift from conventional cytotoxic drugs to targeted

\footnotetext{
* Correspondence: heo1013@snu.ac.kr

${ }^{\dagger}$ Equal contributors

'Seoul National University College of Medicine, Seoul, Korea

${ }^{3}$ Department of Internal Medicine, Division of Hematology and Medical

Oncology, Seoul National University Hospital, Seoul National University

College of Medicine, 101 Daehak-ro, Jongno-gu, Seoul 110-744, Republic of

Korea

Full list of author information is available at the end of the article
}

therapies, including monoclonal antibodies and tyrosine kinase inhibitors, in the application of new drugs for cancer treatment $[5,6]$.

Considering that many new anti-cancer drugs are used to provide modest survival benefits and sometimes solely for the purpose of palliative treatment, cost-effectiveness must be addressed in addition to clinical efficacy $[7,8]$. For example, Moore et al. reported a statistically significant survival benefit of 0.33 months (6.24 vs. 5.91 months) for erlotinib plus gemcitabine compared to gemcitabine alone for first-line treatment of advanced pancreatic cancer [9]. However, the result of this finding regarding the value of erlotinib's small survival benefit has been controversial; the question remains whether we should pay for a drug that improves survival by a median of 10 days with 
an incremental cost-effectiveness ratio (ICER) of up to $\$ 500,000$ per year of life saved [8]. To provide guidelines for such kinds of questions, many countries have adopted evidence-based health technology assessment (HTA) programs that analyze the clinical and cost-effectiveness of selected medical technologies to serve as part of the basis for their recommendations [3,10-12]. Using their national assessment programs, France, Germany, and the United Kingdom (UK) have decided not to reimburse erlotinib for first-line treatment of advanced pancreatic cancer, whereas Korea, Japan, and the United States (US) have chosen to reimburse this indication.

As mentioned above, it is noteworthy that even with the same clinical evidence for anti-cancer drugs, reimbursement policies vary among countries [13] because the criteria of cost-effectiveness and additional costs are country-specific and difficult to standardize [14]. The goal of this study was to compare the pattern of publicly funded cancer drug programs in ten countries, and to identify the major factors that explain the differences according to the perspective of each country's health care system.

\section{Methods}

\section{Countries and drug indications}

For this study, we selected countries that have both universal health care and national or regional public drug reimbursement programs funded by general taxation or premiums. The following ten countries with significant structural and cultural differences in regards to their respective health care system were included: Australia, Canada (Ontario), France, Germany, Japan, Korea, Sweden, Taiwan, the UK, and the US. All countries except Taiwan are the Organization for Economic Co-operation and Development (OECD) member countries; Taiwan was included to better balance the Eastern and Western countries selected for this study. The US was included for comparative purposes, although it has a multi-payer system comprised of private insurance and social insurance programs, with Medicare covering people over 65 years of age and social welfare programs, such as Medicaid, available for low-income people. However, it is not the case for private insurers or indeed for the tens of millions of US citizens that are uninsured. Canada is also unique because drug reimbursement is the responsibility of each province and territory. This study chose to include Ontario to represent Canada, as it is Canada's most populated province.

In choosing the drugs, we identified molecularly targeted anti-cancer drugs that were approved after 2004 and are variably used in our ten countries of interest. The following thirteen anti-cancer drugs were selected: bevacizumab, cetuximab, crizotinib, dasatinib, erlotinib, imatinib, lapatinib, lenalidomide, nilotinib, pemetrexed, sorafenib, sunitinib, and temsirolimus. We then selected their 19 indications to ensure coverage of a variety of both solid and hematologic malignancies, and mechanisms of action. These indications have evidence of clinical efficacy with modest survival benefit (Table 1) and a resulting ICER in the range of $\$ 15,000 \sim \$ 450,000$. Herceptin for breast cancer, and rituximab for malignant lymphoma were not included because most countries reimburse both drugs without much controversy. Some new drugs were excluded, because they were available only in selected countries.

\section{Reimbursed indications}

The approval years of reimbursement for the 13 anticancer drugs were obtained from drug registries of the following authorities of ten countries (as of February 3, 2013): Australia, Pharmaceutical Benefits Scheme in consultation with Pharmaceutical Benefits Advisory Committee (PBAC) [15]; Canada, Ontario Guidelines for Economic Analysis of Pharmaceutical Products in consultation with Ministry of Health and Long-Term Care [16-19]; France, The Haute Autorité de santé in consultation with the Transparency Comission [20]; Germany, Federal Ministry of Health in consultation with the Joint Federal Committee (G-BA) [21] and Institute for Quality \& Efficiency in Health Care [22]; Japan, The Ministry of Health, Labour and Welfare in consultation with Chuikyo [23]; Korea, Korea Food \& Drug Administration in consultation with Health Insurance Review \& Assessment Service [24]; Sweden, Dental and Pharmaceutical Benefits Agency-TLV [25]; Taiwan, Bureau of National Health Insurance in consultation with Drug Beneficiary Committee and Center for Drug Evaluation [26]; the UK, National Health Service in consultation with National Institute for Health and Care Excellence (NICE) [27]; and the US, Food and Drug Administration (FDA) [28]. After identifying insurance coverage data, some of the collected data were then verified by the health care authorities through personal email communications.

The term "reimbursement approval year" refers to the date that the indication was granted reimbursement authorization by each country's governmental regulatory bodies, such as the HTA agencies. In the case of the US, the date of FDA approval was used. However, it should be noted that FDA approval for a certain cancer drug does not necessarily mean that the drug is reimbursed. The US Centers for Medicare and Medicaid Services typically include all US FDA-approved medications on their formulary, through an evidence-based process without the analysis of cost-effectiveness [29]. On the other hand, private health care plans make formulary decisions individually and these processes vary widely. Because they do not make such information available to the public, it was not possible to find the date of reimbursement that represented the US as a whole. 
Table 1 Reimbursement approval year for indications of 13 anti-cancer drugs in 10 countries (as of February 3, 2013)

\begin{tabular}{|c|c|c|c|c|c|c|c|c|c|c|c|}
\hline \multirow[t]{2}{*}{ Drug } & \multirow[t]{2}{*}{ Indications } & \multicolumn{10}{|l|}{ Countries } \\
\hline & & Australia & Canada (Ontario) & France & Germany & Japan & Korea & Sweden & Taiwan & UK & US $^{*}$ \\
\hline \multirow[t]{4}{*}{ Bevacizumab } & $\begin{array}{l}\text { Colorectal cancer : with irinotecan, } \\
\text { fluorouracil, and leucovorin }\end{array}$ & No & 2009 & 2005 & 2009 & 2007 & No & No & 2011 & No & 2004 \\
\hline & $\begin{array}{l}\text { Colorectal cancer : with oxaliplatin, } \\
\text { fluorouracil, and folinic acid }\end{array}$ & 2008 & 2009 & 2008 & 2009 & 2009 & No & No & No & No & 2006 \\
\hline & $\begin{array}{l}\text { NSCLC : 1st line with platinum-based } \\
\text { chemotherapy }\end{array}$ & No & No & 2008 & 2009 & 2009 & No & No & No & No & 2006 \\
\hline & $\begin{array}{l}\text { Renal cell carcinoma : 1st line with } \\
\text { interferon-a }\end{array}$ & No & No & 2008 & 2009 & No & No & No & No & No & 2009 \\
\hline \multirow[t]{3}{*}{ Cetuximab } & Colorectal cancer : with irinotecan & 2010 & 2011 & 2009 & 2009 & 2008 & No & No & 2009 & No & 2004 \\
\hline & $\begin{array}{l}\text { Colorectal cancer (K-RAS wild type): } \\
\text { 1st line with oxaliplatin, fluorouracil, } \\
\text { and folinic acid }\end{array}$ & 2010 & No & 2009 & 2009 & 2010 & No & No & No & 2009 & 2012 \\
\hline & $\begin{array}{l}\text { Head and neck cancer (squamous } \\
\text { cell carcinoma) : 1st line with } \\
\text { platinum-based chemotherapy }\end{array}$ & 2007 & 2011 & 2010 & No & No & No & No & 2009 & No & 2011 \\
\hline Crizotinib & $\begin{array}{l}\text { NSCLC (ALK fusion positive): 2nd } \\
\text { line (vs. docetaxel) }\end{array}$ & No & No & No & No & No & No & No & No & No & 2011 \\
\hline Dasatinib & $\begin{array}{l}\text { Chronic myeloid leukemia, chronic } \\
\text { phase: 1st line }\end{array}$ & 2009 & 2008 & 2007 & No & 2009 & 2008 & 2011 & 2009 & No & 2010 \\
\hline Erlotinib & $\begin{array}{l}\text { Pancreatic cancer : 1st line with } \\
\text { gemcitabine }\end{array}$ & 2012 & No & No & No & 2011 & 2010 & No & No & No & 2005 \\
\hline Imatinib & $\begin{array}{l}\text { Gastrointestinal stromal tumor: } \\
\text { Adjuvant therapy }\end{array}$ & 2011 & 2008 & 2009 & No & No & 2010 & 2009 & 2011 & no & 2008 \\
\hline Lapatinib & $\begin{array}{l}\text { Breast cancer with HER2 } \\
\text { overexpression: } 2 \text { nd line with } \\
\text { capecitabine }\end{array}$ & No & No & 2008 & No & 2009 & 2010 & No & No & No & 2007 \\
\hline Lenalidomide & Multiple myeloma : 1st-line & No & 2009 & No & No & 2010 & No & 2008 & No & 2009 & 2006 \\
\hline Nilotinib & $\begin{array}{l}\text { Chronic myeloid leukemia, chronic } \\
\text { phase: } 1 \mathrm{st} \text {-line }\end{array}$ & 2011 & 2012 & 2008 & 2011 & 2010 & 2011 & 2008 & 2012 & 2012 & 2007 \\
\hline \multirow[t]{2}{*}{ Pemetrexed } & NSCLC: Maintenance treatment & No & 2008 & 2008 & No & 2009 & No & No & No & 2010 & 2009 \\
\hline & $\begin{array}{l}\text { NSCLC (for non-squamous } \\
\text { histology): 1st line with } \\
\text { cisplatin }\end{array}$ & 2009 & 2008 & 2008 & No & 2009 & 2010 & No & 2009 & 2009 & 2008 \\
\hline Sorafenib & Liver cancer : 1st line & 2008 & 2008 & 2008 & 2009 & 2009 & 2011 & No & No & No & 2007 \\
\hline Sunitinib & Renal cell carcinoma: 1st line & 2010 & 2008 & 2006 & 2009 & 2008 & 2007 & 2006 & 2010 & 2009 & 2006 \\
\hline Temsirolimus & $\begin{array}{l}\text { Renal cell carcinoma : 1st-line for } \\
\text { poor prognosis patients }\end{array}$ & No & 2011 & 2008 & 2009 & 2010 & 2011 & No & No & No & 2007 \\
\hline
\end{tabular}

Abbreviations: UK United Kingdom, US United States, NSCLC non-small cell lung cancer.

${ }^{*}$ For United States, Food and Drug Administration (FDA) approval dates are used. However, the fact that FDA approved a certain cancer drug does not mean that that drug is reimbursed.

\section{Incremental cost-effectiveness ratio}

The ICER is commonly used to compare treatments across various indications in cost-effective analysis. The ICER is defined as the ratio of additional costs to incremental benefits of a treatment, and is usually measured as the cost per quality-adjusted life-year (QALY) [30]. The ICER data for each indication were retrieved from the information made available by health authorities online.

\section{Social health insurance systems}

Social health insurance systems of each country were categorized in order to see how they correlated with reimbursement decisions regarding expensive anti-cancer drugs. There are three different types of health care systems based on who collects and provides health care: 1) A multi-payer system comprised of the government-run programs (the dominant insurer) and the private insurances: the government is neither the main healthcare provider nor the collector of money for health care. Individuals have the responsibility to be self-insured; 2) Social health insurance system: the direct provider of health care is not the government, but the government has the financial power to purchase private or public insurance for the people. The fact that the government plays a critical role 
in the collection of funds for health care does not necessarily mean that the government provides care; and 3) Publicly funded health system: the government directly manages and operates facilities for health care and performs the insurance function of reimbursement. The government runs the single insurance scheme but does not provide the care [31].

For the ten countries of interest, the financing systems were analyzed to determine whether they affected the reimbursement decision of expensive anti-cancer drugs. For each country, the HTA authority was identified and the date of implementation of HTA in the decision making process was also noted. The form of health security was also assessed to categorize countries into different operation systems: customer sovereignty model, social health insurance, and national healthcare service. To estimate the magnitude of expenditure on health care, we also investigated the health expenditure of ten countries using data from the OECD [32].

\section{Calculation of reimbursement adequacy index}

There are two aspects in assessing the reimbursement policy of each country. The first aspect considers how well the policy handles reimbursements for indications that are considered cost-effective. The second aspect considers how well the policy does in not reimbursing indications that are considered cost-ineffective.

In order to assess the cost-effectiveness of reimbursement decisions for the selected anti-cancer drug indications across different countries, we applied a statistical method for measuring the accuracy of diagnostic procedures and calculated the reimbursement adequacy index (RAI) for each country as follows. In case of the US, however, we did not calculate its RAI in that the US has no single dominant health insurance program.

Test outcomes reflect whether an indication is reimbursed or not. To determine the condition status, each indication was assessed to be either cost-effective or cost-ineffective. Although there is no reliable empirical basis on deciding cost-effectiveness thresholds in healthcare, WHO considers that technologies for which the ICER is more than three times a country's gross domestic product (GDP) per capita will invariably be cost ineffective $[6,33]$. Therefore, the indications with ICERs less than three times a country's GDP per capita were considered to be cost-effective in this study.

RAI is the proportion of cost-effective decisions, either reimbursement of cost-effective indications or non-reimbursement of cost-ineffective indications, out of total indications.

number of reimbursed indications that are cost effective + $R A I=\frac{\text { number of not reimbursed indications that are cost ineffective }}{}$ Total number of indications
For example, the cost-effective threshold in Korea was calculated by multiplying Korea's GDP by $3(\$ 26881 \times 3=$ \$80643). Therefore, the indications with ICERs less than $\$ 80643$ were considered to be cost-effective. For Korea, a $2 \times 2$ table was constructed; the columns represent the condition (cost-effectiveness) and the rows represent the test outcome (reimbursement decision) (Table 2).

$$
\text { RAI Korea }=\frac{3+7}{3+6+3+7}=\frac{10}{19}=0.53
$$

We used Spearman's rank correlation coefficient for the association between the two variables, and considered $P<0.05$ to be statistically significant.

\section{Heatmap plot and clustering}

To cluster the countries with distinct characteristics of reimbursement policies, we used microarray analysis methods and drew a heatmap plot using MultiExperiment Viwer $(\mathrm{MeV})$ version 4.7. First, we made a $10 \times 19$ matrix (10 countries and 19 indications) based on Table 1 . Then, each indication was sorted from the lowest to highest ICER. For hierarchical clustering, we used a metric algorithm and an average linkage as a linkage method.

\section{Ethics statement}

This study does not involve human subjects, human material, or human data, and therefore, does not require ethics approval. All the data used in this study were gathered from sources publicly available online.

\section{Results}

Reimbursed indications

Table 1 shows the information regarding whether each country reimburses a certain indication, and if reimbursed, when each country first approved the reimbursement. Not counting the US, Japan and France were the most likely to reimburse the indications (16/19), whereas Sweden and the UK were the least likely to reimburse them (5/19 and $6 / 19$, respectively).

\section{ICER}

The ICER data was available only in two countries: UK (NICE) and Australia (PBAC). We found NICE to be the most comprehensive and used the ICER from NICE as

Table 2 An example of the calculation of reimbursement adequacy index (RAI) in Korea

\begin{tabular}{lllll}
\hline & & \multicolumn{2}{l}{ Cost-effectiveness } & \\
\cline { 3 - 4 } & & Effective & In-effective & \\
\hline \multirow{2}{*}{ Reimbursement } & Reimbursed & 3 & 6 & 9 \\
& Not reimbursed & 3 & 7 & 10 \\
& & 6 & 13 & 19 \\
\hline
\end{tabular}


the reference values to use with other countries in which the data was not otherwise available. If the ICER was unavailable due to manufacturer's unwillingness (bevacizumab plus platinum-based chemotherapy for advanced non-small cell lung cancer) [34] or unissued appraisal (erlotinib plus gemcitabine for advanced pancreatic cancer), we retrieved the relevant ICER value from PBAC (bevacizumab) [35] or through a literature review (erlotinib) [8]. Table 3 shows the representative ICER for each drug indication in the increasing order of ICER values. We found a strong correlation of reimbursements for indications with lower ICERs $(\rho=-0.68, P=0.001)$; the indication with lower ICER was more likely to be reimbursed (Figure 1).

\section{Social health insurance systems and the reimbursement adequacy index}

Table 4 shows the RAI and social health insurance systems across the ten countries. The UK had the highest RAI scores. Four countries with high RAI scores (UK, Canada, Australia, and Sweden) have health care systems that are all financed mainly by general taxation. On the other hand, the three countries with the lowest RAI scores were Korea, Taiwan, and Germany. In these countries, the social health insurance is financed by payroll tax or premiums rather than general taxation. Interestingly, countries with high RAI scores (UK, Canada, Australia, and Sweden) have incorporated HTA since the 1990's, whereas countries with low RAI scores (Korea, Taiwan, and Germany) have only recently incorporated HTA. With regard to Germany, the G-BA is the supreme decisionmaking body; however, the G-BA does not conduct economic evaluations requiring an ICER for informing coverage decisions except for those few cases where there is a disagreement between the company and the insurer, the G-BA. Similar to Germany, France has a HTA agency that applies an evaluation process based on evidence, not comparative cost effectiveness.

We found a significant correlation in which the RAI decreased as the proportion of pharmaceutical expenditure among total health care expenditure increased $(\rho=-0.65$, $P=0.04$ ) (Table 5) (Figure 2). The simple price of the drug $(P=0.24)$, GDP $(P=0.19)$, and the proportion of healthcare expenditure among GDP $(P=0.81)$ did not relate to RAI significantly. Regarding the pattern of reimbursement status (Figure 1), we tried to group countries into those with similar patterns: A) UK and Sweden; B) Australia, Canada, Taiwan, and Korea; C) Germany, Japan, France, and the US. However, we did not find any correlation between

Table 3 Representative incremental cost-effectiveness ratio for each drug indication in increasing order

\begin{tabular}{lll}
\hline Drug & Indications & ICER ( in US\$)* \\
\hline Nilotinib & Chronic myeloid leukemia, chronic phase: 1st-line & 17,314 \\
Imatinib & Gastrointestinal stromal tumor: Adjuvant therapy & 29,591 \\
Cetuximab & Colorectal cancer (K-RAS wild type): 1st line with oxaliplatin, fluorouracil, and folinic acid & 42,026 \\
Pemetrexed & NSCLC (for non-squamous histology): 1st line with cisplatin & 44,451 \\
Lenalidomide & Multiple myeloma: 1st-line & 68,941 \\
Pemetrexed & NSCLC: Maintenance treatment & 73,978 \\
Sorafenib & Liver cancer: 1st line & 82,792 \\
Sunitinib & Renal cell carcinoma: 1st line & 85,572 \\
Lapatinib & Breast cancer with HER2 overexpression: 2nd line with capecitabine & 93,496 \\
Bevacizumab & Colorectal cancer: with irinotecan, fluorouracil, and leucovorin & 98,937 \\
Bevacizumab & Colorectal cancer: with oxaliplatin, fluorouracil, and folinic acid & 110,967 \\
Dasatinib & Chronic myeloid leukemia, chronic phase: 1st-line & 118,050 \\
Cetuximab & Colorectal cancer: with irinotecan & 121,528 \\
Temsirolimus & Renal cell carcinoma: 1st-line for poor prognosis patients & 128,595 \\
Bevacizumab & Renal cell carcinoma: 1st line with interferon-a & 131,070 \\
Crizotinib & NSCLC (ALK fusion positive): 2nd line (vs. docetaxel) & 158,133 \\
Bevacizumab & NSCLC: 1st line with platinum-based chemotherapy & $196,000^{\dagger}$ \\
Cetuximab & Head and neck cancer (squamous cell carcinoma) : 1st line with platinum-based chemotherapy & 261,767 \\
Erlotinib & Pancreatic cancer: 1st line with gemcitabine & $430,000^{\ddagger}$ \\
\hline
\end{tabular}

ICER, Incremental Cost Effectiveness Ratio; NSCLC, non-small cell lung cancer.

*Most ICER values except two indications were retrieved from the National Institute for Health and Clinical Excellence in United Kingdom (costs are expressed in US dollars; $\mathbf{£} 1$ equals $\$ 1.574$ (as of January 29,2013 )).

${ }^{\dagger}$ This value was from the Pharmaceutical Benefits Advisory Committee in Australia. (Canadian $\$ 1$ equals US \$0.98) http://www.pbs.gov.au/info/industry/listing/ elements/pbac-meetings/psd/2011-03/pbac-psd-bevacizumab-march11.

${ }^{\ddagger}$ This value was from Miksad RA et al. J Clin Oncol 25:4506-7; author reply 4508, 2007. 


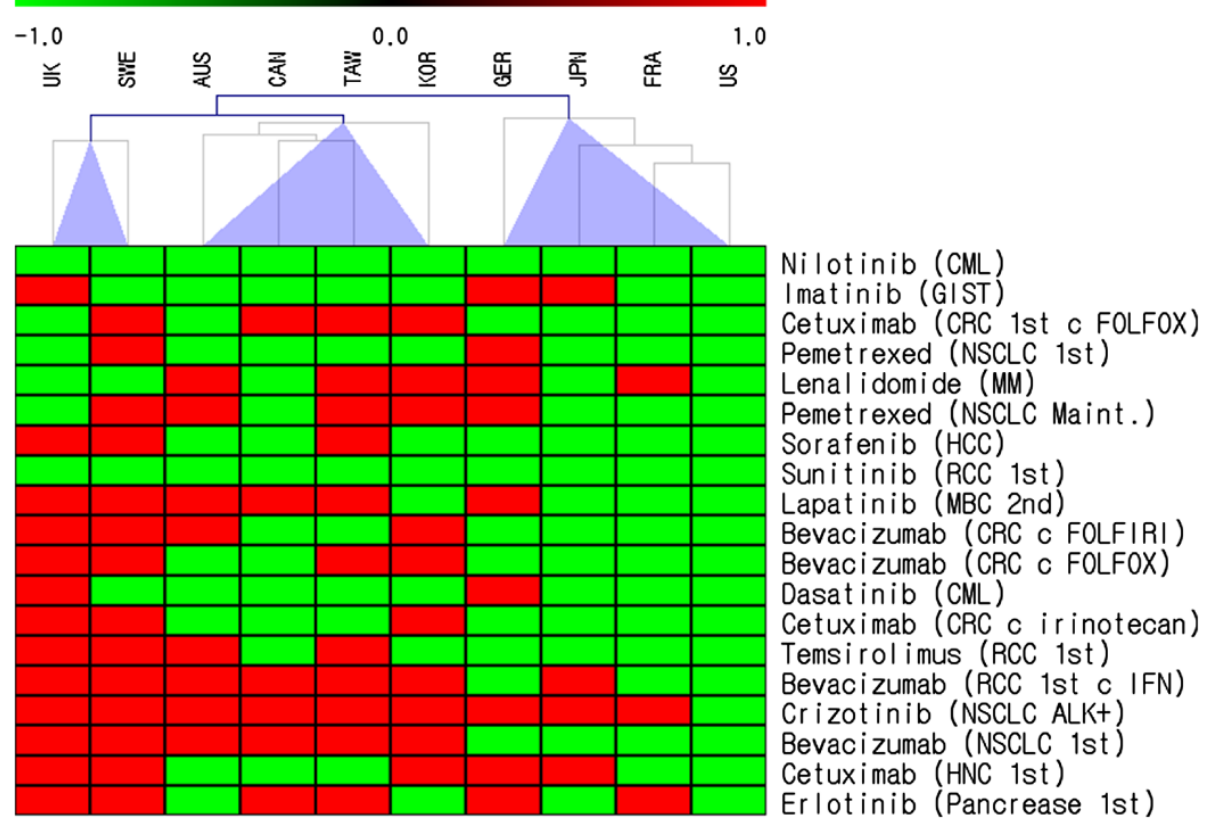

Figure 1 Clustering of countries according to the pattern of reimbursement status. The color green is used to show that the indication is reimbursed in a given country, and the color red signifies the indications that are not reimbursed. Each indication is sorted according to its ICER, from the lowest (on top) to highest (on bottom).

clustering results and other indices including the RAI, the date of implementation of HTA systems, and other parameters in Table 5 (unpublished data).

\section{Discussion}

The present study shows that reimbursement policies for anti-cancer drugs vary among countries even though they rely on the same clinical evidence of those drugs. Although most counties have adopted evidence-based HTA programs to estimate the cost-effectiveness of anti-cancer drugs, each HTA suggests different recommendations. Overall, there was a strong correlation of reimbursements in indications with lower ICERs.

Among the many factors that might influence reimbursement policies, we focused on ICER, a surrogate index for cost-effectiveness, because the ICER is regarded as wellestablished evidence for basing resource allocation decisions [30]. As healthcare costs continue to rise, recent clinical trials have tried to integrate ICER into their methods to provide further evidence of potential benefits along with clinical efficacy [36]. Therefore, the decision to place emphasis on ICER seemed to be a rational approach for analyzing the diverse patterns of reimbursement decisions.

We tried to collect ICER data from each country and compare them, but most countries did not disclose reimbursement policies and related data. The UK, Australia, Canada, and Sweden apply Cost-Effectiveness criteria in a fairly rigorous way; on the other hand, France and Germany measure the added clinical value on a 5-point scale, which is then used as a guide for price negotiations. France and Germany do not calculate the ICER at all, and in this sense, the HTA agencies in France and Germany do not conduct economic evaluations for informing reimbursement. The UK and Australia do the most thorough job of establishing an ICER database online. Thus, ICER data from NICE (UK) or PBAC (Australia) were retrieved. In our study, the representative ICER data from NICE were used as the standard for comparison instead of using ICER data from different sources. However, the ICER estimates might vary between countries depending on which current practice is being used as a control, and on assumptions about survival estimates for a new regimen. In addition, utilities for estimating incremental health gain have national differences in their weighting [37]. Thus, other determinants such as controls, real world effectiveness estimates, unit costs, resource use patterns, patient preferences, and the threshold might account for differences in the ICERs and each country's respective reimbursement decisions. For the reasons mentioned above, there are inherent limitations to extrapolating NICE's ICER values [6]. Furthermore, because the RAI was calculated based on the ICERs mainly retrieved from NICE (UK), the ranking reflects how well each country adheres to NICE's method of evaluating cost-effectiveness. By using this standard, there is an inherent assumption 
Table 4 Reimbursement adequacy index and social health insurance system

\begin{tabular}{|c|c|c|c|c|c|c|c|c|c|}
\hline & UK & Canada & Australia & Sweden & France $^{*}$ & Japan & Korea & Taiwan & Germany $^{*}$ \\
\hline $\begin{array}{l}\text { Reimbursement } \\
\text { adequacy index }\end{array}$ & 0.79 & 0.68 & 0.63 & 0.58 & 0.58 & 0.58 & 0.53 & 0.53 & 0.47 \\
\hline Financing system & $\begin{array}{l}76 \% \text { General tax }+18 \% \\
\text { National insurance }+3 \% \\
\text { user charge }\end{array}$ & $\begin{array}{l}100 \% \text { General } \\
\text { tax }\end{array}$ & $\begin{array}{l}98.5 \% \text { General tax } \\
+1.5 \% \text { Levy }\end{array}$ & $100 \%$ General tax & $\begin{array}{l}33 \% \text { General tax }+43 \% \\
\text { National insurance }+ \\
\text { Levies + other social } \\
\text { security }\end{array}$ & Premium & Premium & Premium & Premium \\
\hline $\begin{array}{l}\text { Health technology } \\
\text { assessment (HTA) }\end{array}$ & $\begin{array}{l}\text { Government } \\
\text { independent }\end{array}$ & $\begin{array}{l}\text { Government } \\
\text { independent }\end{array}$ & $\begin{array}{l}\text { Government } \\
\text { agency }\end{array}$ & $\begin{array}{l}\text { Government } \\
\text { agency }\end{array}$ & $\begin{array}{l}\text { Government } \\
\text { agency }\end{array}$ & N/A & $\begin{array}{l}\text { Government } \\
\text { agency }\end{array}$ & $\begin{array}{l}\text { Government } \\
\text { agency }\end{array}$ & $\begin{array}{l}\text { Government } \\
\text { independent }\end{array}$ \\
\hline $\begin{array}{l}\text { Date of HTA } \\
\text { foundation }\end{array}$ & 1999 & 1990 & 1993 & 1987 & 2004 & N/A & 2009 & 2007 & 2004 \\
\hline $\begin{array}{l}\text { Form of Health } \\
\text { Security }\end{array}$ & $\begin{array}{l}\text { National Healthcare } \\
\text { Service }\end{array}$ & $\begin{array}{l}\text { Social Health } \\
\text { Insurance }\end{array}$ & $\begin{array}{l}\text { Social Health } \\
\text { Insurance }\end{array}$ & $\begin{array}{l}\text { National Healthcare } \\
\text { Service }\end{array}$ & $\begin{array}{l}\text { Social Health } \\
\text { Insurance }\end{array}$ & $\begin{array}{l}\text { Social Health } \\
\text { Insurance }\end{array}$ & $\begin{array}{l}\text { Social Health } \\
\text { Insurance }\end{array}$ & $\begin{array}{l}\text { Social Health } \\
\text { Insurance }\end{array}$ & $\begin{array}{l}\text { Social Health } \\
\text { Insurance }\end{array}$ \\
\hline
\end{tabular}

\section{$\mathrm{N} / \mathrm{A}$, not available.}

*Germany and France have the HTA agencies that apply an evaluation process based on evidence but not based on comparative cost effectiveness. 
Table 5 Health expenditure of each country

\begin{tabular}{|c|c|c|c|c|c|c|c|c|c|}
\hline & UK & Canada & Australia & Sweden & France & Japan & Korea & Taiwan & Germany \\
\hline GDP per capita in US\$ (2009) & 34397 & 37773 & 39833 & 37255 & 33785 & 32061 & 26881 & $32214^{*}$ & 35643 \\
\hline Total expenditure on health (TEH), \% of GDP (2009) & 9.8 & 11.4 & 9.1 & 9.9 & 11.7 & 9.5 & 6.9 & $6.4^{*}$ & 11.7 \\
\hline Public expenditure on health, \% of TEH (2009) & 83.4 & 70.9 & 68.5 & 81.5 & 76.9 & 80.5 & 58.2 & $26.6^{*}$ & 76.9 \\
\hline $\begin{array}{l}\text { Out-of-pocket expenditure (households) on health, \% of TEH } \\
\text { (2009) }\end{array}$ & 9.1 & 14.2 & 18.6 & 16.4 & 7.4 & 16 & 32.4 & $38.1^{*}$ & 13 \\
\hline $\begin{array}{l}\text { Pharmaceutical expenditure and other medical non-durables, \% } \\
\text { of TEH (2009) }\end{array}$ & $11.8^{*}$ & 17 & 14.7 & 12.7 & 16.1 & 20.8 & 22.5 & $25^{*}$ & 14.9 \\
\hline Life expectancy of both sexes at birth in years (2009) & 80.4 & $80.8^{*}$ & 81.6 & 81.4 & 81.1 & 83 & 80.4 & $79^{*}$ & 80.3 \\
\hline
\end{tabular}

Abbreviations: GDP gross domestic product, UK United Kingdom, US United States.

Source: OECD website (except Taiwan) from http://stats.oecd.org/Index.aspx?DataSetCode=SHA.

For Taiwan, refers to 文犲苹外，台灣醫療保健支出成長率的分析：醫療通膨，質量與公本性，台灣衛誌2012, Vol3，No1. "When the data for 2009 was not available, the relevant data from 2008 was used.

that the UK does the best in making cost-effectiveness decisions and at the same time, the UK inevitably obtains the highest RAI according to our method. This is by far the greatest weakness of the analysis.

We found that indications with high cost-effectiveness values (lower ICERs) were more likely to be reimbursed, which suggests that each country considers cost-effectiveness in addition to clinical efficacy when deciding the reimbursement of a certain drug. Given the finite financial resources and rising costs of anti-cancer drugs, each country must be economical when deciding reimbursement policies for each anti-cancer drug. Cheema et al. documented international variability in the ability to access cancer drugs by measuring the number of licensed indications reimbursed by public payers [13]. However, they did not go so far as to compare the pattern of reimbursement decisions using a mathematical algorithm to systematically analyze a country's efficiency in making cost-effective coverage decisions with regard to ICER. Although the findings of our study may have been expected, our study attempts to compare reimbursement policies of different countries with regard to cost-effectiveness by using a systematic approach of calculating RAI.

We tried to cluster the countries according to the pattern of reimbursement using microarray analysis methods (Figure 1). However, we could not find any correlation between clustering results and other indices, including the RAI, government dependency on HTA, and other parameters. This suggests that the reimbursement decision derived from estimates of cost-effectiveness cannot be explained by one index alone.

There are many other factors that influence the decision of authorities to fund certain drugs besides the ICER: the patient's demographics (i.e. drugs with higher ICERs tend

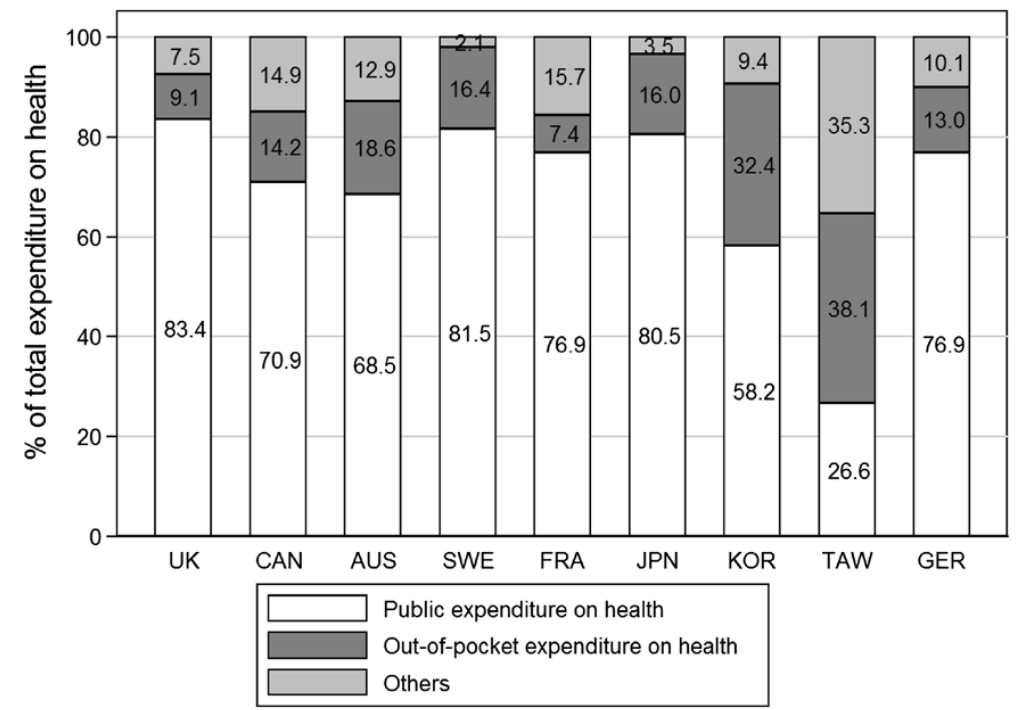

Figure 2 Proportion of total expenditure on health. Countries are arranged according to their respective reimbursement adequacy index score (higher scores on the left and lower scores on the right). 
to be more frequently approved for pediatric patients with cancer), the availability of alternative treatments, and the consideration of new drugs with its impact on the jurisdiction's healthcare budget. Undoubtedly, the decision to approve a new drug is multifaceted and multifactorial. Nevertheless, our findings show that the cost-effectiveness is taken into prime consideration in many countries (especially countries which have adopted HTA since the 1990's).

We introduced the concept of RAI to estimate how efficiently each country decides to reimburse anti-cancer drugs. Our study found an interesting relationship between RAI scores and social health insurance systems. Specifically, the four countries that had high RAI scores, UK, Canada, Australia, and Sweden have health systems that are financed by general taxation. Additionally, countries with health care systems that are financed by general taxation have operated HTA longer than those that are financed by premium. This shows that countries with a health system financed by general taxation are more likely to consider the cost-effectiveness of certain anti-cancer drugs. Considering the fact that no health insurance system can cover every medical intervention despite the clinical benefit, our findings reflect the realities of current health systems.

Faden et al., who had a similar point of view, compared the UK and US experiences with expensive cancer drugs, and found that the UK system is fairer and better structured than the US system when dealing with difficult decisions about expensive end-of-life cancer drugs [38]. They emphasized the role of NICE when facing dilemmas for competing clinical or cost-effectiveness of cancer drugs, which supports our findings.

Our study had other limitations. First, the reimbursement status may not be representative of real-world situations. Some cancer drugs are supported by other sources of funding regardless of HTA recommendations. For example, the Cancer Drug Fund in the UK supports some indications that go against the policies by NICE, although these are not national decisions. Second, the selection of study countries and drug indications are inherent to selection bias. Given the vast number of novel molecular targeted anti-cancer drugs available in the market of the ten countries, it was challenging to select drugs and their indications in a systemic way with clear selection criteria. Furthermore, because the reimbursement decision and the year of reimbursement were found using internet searches, it was very challenging to find reliable information for the purpose of our study. Third, the representative ICER we presented may not perfectly reflect the current appraisal of each country because of the aforementioned reasons. Lastly, the threshold determined to be costeffective (ICERs being less than three times a country's GDP per capita) is arbitrary to use as a measure of cost effectiveness irrespective of the country's health expenditure as a proportion of GDP; for example, the presence of a functional generics market would increase the productivity of the system with regard to branded drugs. Recent empirical research in the UK showed that the threshold is likely to be half the country's GDP per capita [39]. However, despite these limitations, we tried to get the gist using the best available evidence.

\section{Conclusion}

Although reimbursement policies for anti-cancer drugs vary among countries, we found a strong correlation of reimbursements favoring indications with lower ICERs. Countries that have health systems financed by general taxation adopt cost-effectiveness as evidenced by healthcare resource allocation.

\section{Competing interests}

The authors declare that they have no competing interests.

\section{Authors' contributions}

CSL and YGL participated in study design, data collection, data analysis and interpretation, and led on writing this manuscript. YK participated in study design and data interpretation and assisted in writing this paper. DSH conceived of and led this study, participated in study design and data interpretation, and led on writing this manuscript. All authors read and approved the final manuscript.

\section{Acknowledgements}

The authors wish to thank Soon-II Kwon for assistance of data collection and analysis.

This study was supported by a grant of the Korea Healthcare technology R\&D Project, Ministry of Health and Welfare, Republic of Korea. (A062260).

This study was presented in part at the 2013 ASCO Annual Meeting, May 31-June 4, 2013, Chicago, Illinois.

\section{Author details}

${ }^{1}$ Seoul National University College of Medicine, Seoul, Korea. ${ }^{2}$ Department of Internal Medicine, Kangbuk Samsung Medical Center, Sungkyunkwan University School of Medicine, Seoul, Korea. ${ }^{3}$ Department of Internal Medicine, Division of Hematology and Medical Oncology, Seoul National University Hospital, Seoul National University College of Medicine, 101 Daehak-ro, Jongno-gu, Seoul 110-744, Republic of Korea.

Received: 21 March 2014 Accepted: 10 November 2014

Published online: 29 November 2014

\section{References}

1. Bach PB: Limits on Medicare's ability to control rising spending on cancer drugs. N Engl J Med 2009, 360(6):626-633.

2. Siddiqui M, Rajkumar SV: The high cost of cancer drugs and what we can do about it. Mayo Clin Proc 2012, 87(10):935-943.

3. Drummond MF, Mason AR: European perspective on the costs and cost-effectiveness of cancer therapies. J Clin Oncol 2007, 25(2):191-195.

4. Meropol NJ, Schulman KA: Cost of cancer care: issues and implications. J Clin Oncol 2007, 25(2):180-186.

5. Savage P: Development and economic trends in cancer therapeutic drugs in the UK from 1955 to 2009. J Oncol Pharm Pract 2012, 18(1):52-56.

6. Rawlins M: Paying for modern cancer care-a global perspective. Lancet Oncol 2007, 8(9):749-751.

7. Fojo T, Grady C: How much is life worth: cetuximab, non-small cell lung cancer, and the $\$ 440$ billion question. J Natl Cancer Inst 2009, 101(15):1044-1048.

8. Miksad RA, Schnipper L, Goldstein M: Does a statistically significant survival benefit of erlotinib plus gemcitabine for advanced pancreatic cancer translate into clinical significance and value? J Clin Oncol 2007, 25(28):4506-4507. author reply 4508. 
9. Moore MJ, Goldstein D, Hamm J, Figer A, Hecht JR, Gallinger S, Au HJ, Murawa P, Walde D, Wolff RA, Campos D, Lim R, Ding K, Clark G, Voskoglou-Nomikos T, Ptasynski M, Parulekar W: Erlotinib plus gemcitabine compared with gemcitabine alone in patients with advanced pancreatic cancer: a phase III trial of the National Cancer Institute of Canada Clinical Trials Group. J Clin Oncol 2007, 25(15):1960-1966.

10. Sullivan SD, Watkins J, Sweet B, Ramsey SD: Health technology assessment in health-care decisions in the United States. Value Health 2009. 12(Suppl 2):S39-S44

11. Littlejohns P, Barnett D, Longson C: Excellence UKNIfC: the cancer technology appraisal programme of the UK's National Institute for Clinical Excellence. Lancet Oncol 2003, 4(4):242-250.

12. Velasco-Garrido M, Kristensen FB, Nielsen CP, Busse R: Health Technology Assessment and Health Policy-making in Europe: Current Status, Challenges and Potential. Copenhagen: European Observatory on Health Systems and Policies; 2008.

13. Cheema PK, Gavura S, Migus M, Godman B, Yeung L, Trudeau ME: International variability in the reimbursement of cancer drugs by publically funded drug programs. Curr Oncol 2012, 19(3):e165-e176.

14. Mullins CD, Ogilvie S: Emerging standardization in pharmacoeconomics. Clin Ther 1998, 20(6):1194-1202. discussion 1192-1193.

15. Department of Health and Ageing (DHA) Pharmaceutical Benefits Scheme. [Available online at: http://www.pbs.gov.au/pbs/home; cited May 10, 2013]

16. Ontario Guidelines for Economic Analysis of Pharmaceutical Products. [Available online at: http://www.health.gov.on.ca/en/pro/programs/drugs/ dsguide/docs/economic.pdf; cited May 10, 2013]

17. New Drug Funding Program. [Available online at: https://www.cancercare on.ca/toolbox/drugs/ndfp; cited May 10, 2013]

18. Drugs funded by Ontario Drug Benefit (ODB) Program. [Available online at: http://www.health.gov.on.ca/en/pro/programs/drugs/odbf_eformulary. aspx; May 10, 2013]

19. Ministry of Health and Long-Term Care Ontario Public Drug Programs: Exceptional Access Program. [Available online at: http://www.health.gov. on.ca/en/pro/programs/drugs/eap_mn.aspx; cited May 10, 2013]

20. The Haute Autorité de santé. [Available online at: http://www.has-sante.fr/; cited May 10, 2013]

21. Gemeinsamer Bundesausschuss. [Available online at: http://www.g-ba.de/; cited May 10, 2013]

22. Institute for Quality \& Efficiency in Health Care. [Available online at: https://www.iqwig.de/; cited May 10, 2013]

23. Pharmaceuticals and Medical Device Agency (PMDA) Approved Products. [Available online at: http://www.pmda.go.jp/english/service/approved.html; cited May 10, 2013]

24. Reimbursement criteria for anti-cancer drugs. [Available online at: http:// www.hira.or.kr/eng/index.html; cited May 10, 2013]

25. Läkemedelsförmånsnämnden. [Available online at: http://www.tlv.se/; cited May 10, 2013]

26. Bureau of National Health Insurance, Department of Health, Execitive Yuan. [Available online at: http://www.nhi.gov.tw/; cited May 10, 2013]

27. National Institute for Health and Clinical Excellence (NICE) Guidance. [Available online at: http://guidance.nice.org.uk; cited May 10, 2013]

28. FDA Approved Drug Products. [Available online at: http://www.accessdata. fda.gov/scripts/cder/drugsatfda/index.cfm; cited May 10, 2013]

29. Mason A, Drummond M, Ramsey S, Campbell J, Raisch D: Comparison of anticancer drug coverage decisions in the United States and United Kingdom: does the evidence support the rhetoric? J Clin Oncol 2010, 28(20):3234-3238.

30. Folland SGA, Stano M: Chapter 4: Economic Effiencey and Cost-Benefit Analysis. In The Economics of Health and Health Care. 6th edition. Boston: Prentice Hall; 2010

31. Wagstaff A: Social health insurance vs. tax-financed health systems-evidence from the OECD. World Bank Policy Research Working Paper Series, Vol 2009

32. OECD Health Data 2012. [Available online at: http://www.pbs.gov.au/html/ home; cited May 10, 2013]

33. Edejer TT-T, World Health Organization: Making choices in health : WHO guide to cost-effectiveness analysis. Geneva: World Health Organization; 2003.

34. Bevacizumab for the treatment of non-small-cell lung cancer (terminated appraisal). [Available online at: http://www.nice.org.uk/guidance/TA148; cited May 10, 2013]
35. Public Summary Documents by Product in Pharmaceutical Benefits Scheme (PBS). [Available online at: http://www.pbs.gov.au/info/industry/ listing/elements/pbac-meetings/psd/2011-03/pbac-psd-bevacizumabmarch11; cited May 10, 2013]

36. Ramsey S, Willke R, Briggs A, Brown R, Buxton M, Chawla A, Cook J, Glick H, Liljas B, Petitti D, Reed S: Good research practices for cost-effectiveness analysis alongside clinical trials: the ISPOR RCT-CEA Task Force report. Value Health 2005, 8(5):521-533.

37. Szende A, Oppe M, Devlin NJ: EQ-5D value sets: inventory, comparative review and user guide, vol. 2. Dordrecht: Springer; 2007.

38. Faden RR, Chalkidou K, Appleby J, Waters HR, Leider JP: Expensive cancer drugs: a comparison between the United States and the United Kingdom. Milbank Q 2009, 87(4):789-819.

39. Karl C, Steve M, Marta S, Nigel R, Eldon S, Sebastian H, Nancy D, Peter CS, Mark S: Methods for the estimation of the NICE cost effectiveness threshold. In Centre for Health Economics, University of York. 2013.

doi:10.1186/s12913-014-0595-0

Cite this article as: Lim et al.: International comparison of the factors influencing reimbursement of targeted anti-cancer drugs. BMC Health Services Research 2014 14:595.

\section{Submit your next manuscript to BioMed Central and take full advantage of:}

- Convenient online submission

- Thorough peer review

- No space constraints or color figure charges

- Immediate publication on acceptance

- Inclusion in PubMed, CAS, Scopus and Google Scholar

- Research which is freely available for redistribution 